\title{
Art Education and Creations of Artistic Forms. Students' Views on the Course and Its Combination with Cultural Heritage
}

\author{
Maria Kampouropoulou ${ }^{1}$, Persa Fokiali ${ }^{2}$, Ioanna Efstathiou ${ }^{1} \&$ Efstathios Stefos ${ }^{1}$ \\ ${ }^{1}$ Department of Primary Education, University of the Aegean, Rhodes, Greece \\ ${ }^{2}$ Department of Preschool Education Sciences and Educational Design, University of the Aegean, Rhodes, Greece \\ Correspondence: Efstathios Stefos, Department of Primary Education, University of the Aegean, Dimokratias 1, \\ 85100 Rhodes, Greece. Tel: 30-224-109-1451. E-mail: estefos@aegean.gr
}

Received: December 28, 2014 Accepted: January 27, 2014 Online Published: April 14, 2014

doi:10.5539/res.v6n2p7

URL: http://dx.doi.org/10.5539/res.v6n2p7

\begin{abstract}
The goal of this study was to appoint students" views on the lesson, "Art Education and Creations of Artistic forms". In this context, a research was carried out at the University of the Aegean, DepArtment of Primary Education during the first semester of 2013-2014. The lectures included pArt from the basic knowledge, students' involving in Artistic activities and exercises in Traditional Art. Most of the activities were designed to promote Cultural Heritage through Art and the final work was for them to create training manual to be used by students of Primary Education, in order to learn about the local Cultural Heritage. The questionnaire was answered by 149 students pArticipated in the research before and after the lectures and Artistic works they had to carry out. In order to extract the research results, we used statistical software SPSS v.17 offered by the School of Humanities of the University of the Aegean. The analysis showed that most of the students are positive towards following the specific course at the University and believe that it promotes Cultural Heritage and in combine with the economic, social, cultural and sustained development of the country.
\end{abstract}

Keywords: art education, cultural heritage, content analysis

\section{Introduction}

After the Second World War and because of the experiences related to it, wittings on the Artistic treatment turned to the human possibilities of Art. Nowadays, in a world characterized from advertising, media, globalization and huge social changes, education must redefine its role and aim to a strong educational environment able to lead students to a balanced life (Matsagouras, 2003). The Artistic treatment can acquaint children with subtle forms of emotion countless values and life standards and also more insights about human spirit. Through Art Education a child can acquire specific knowledge which allows him/her to explore deeper meanings of visual forms and the importance of preserving Cultural Heritage. The lectures of the course intended to foster students' creativity, produce Artistic work, pArticipate in visual Arts and specially promote Cultural Heritage through Art (Kampouropoulou et al., 2011).

\section{Combining Art in Higher Education with Cultural Heritage}

In modern educational thought, Art is defined as "a body of knowledge" and meanwhile as a development activity. Many scientists believe that Artistic experiences are an average of maturity. Through the lectures students were introduced to the basic concepts of Art and research methods (Chapman, 1993). They were taught how to use materials, tools and resources in a variety of visual forms. They realized the sensitive responsiveness and critical approach and analysis of Artwork and generally the phenomenon of Art. They also understood the Cultural dimensions and contributions of Arts in Culture overtime and the holistic approach of teaching through Art. The lesson was considered more than simply providing Artistic skills, more than a specialization and accumulation of technical knowledge, but was an intellectual process correlation with alternative perceptions (Ardoin, 2002).

Students were trained to study topics related to the Cultural Heritage by getting information and learning, how to translate this information into new creations, so they were given the opportunity to approach the historical concepts (Balta \& Demou, 2002) and also focus and emphasize in Cultural dimension of education, in order not only to create educational material as their last work, but also to prove how important is teaching Art in schools 
so that Cultural Heritage can be promoted (Fokiali et al, 2003). Meanwhile they studied different Artistic areas and got involved in learning experiences and adventures (Girtzi \& Boutidou, 2010).

\section{The Method}

Modern Pedagogical trends based on the development of creativity and freedom of expression, have paved the way for a more direct, efficient cooperation between Art Education and Pedagogy (Dottrens, 1974; Mikropoulos et al., 1994; Robinson, 1990; Rogers, 1995). The Curriculum of the course was based on: Knowledge experiences, Production-Creation, Views-Observation, Cultural Heritage-Artistic Creations. In particular:

- Students were taught the basic characteristics of creativity starting with the fact that all of them are creative persons in relation with their own personality (Bruner, 1966). They were also given the characteristics of creativity according to Guilford, such as, fluency thinking, flexibility, originality of thought, analysiscomposition, transformation, edit - output, organization-complexity (Guilford, 1952). As they will become teachers themselves in Primary Education, it was displayed the need to connect Art Education issues that promote creativity and critical thinking with life and children's' experiences and in authentic contexts and situations. The theory of the course included visual basic principles as, contacting colors, shading, using pencil and draw, tension, motion, space, principles of composition, etc. They also proceed in activities such as, drawing, painting, printmaking, three dimensional constructing, collage, illustration. Their first exercise was to draw and paint one of the arches of the central gate of the University. The purpose was, students to be able to use Visual forms making various or specific choices and to be able to recognize various forms of Visual Art - Techniques (Form Data) in the environment, objects and works of Art.

- They learnt about the several materials (pencils, markers, pastels, textiles, sponges, nature materials, computer etc.), they can use to their creations. Our purpose was for them to understand the characteristics and properties of the several materials and the capabilities of each and every one and the method of using them in combination with New Technologies (Kampouropoulou-Savvaidou, 2007; Kampouropoulou et al., 2011). Also to discover their skills, develop them and be able to use and transform materials to new creations. It was specially notified to them that colors have a symbolic function connected to the maximum extent with Cultural conditions of time and space created. They are symbolically charged in a constitutional level and that their juxtaposition creates meanings (Skarpelos, 2000).

- They were taught how to observe (describe, explore, study), the Cultural elements in the environment and how to combine Art with Cultural Heritage and the way to promote Art Education with it as future teachers in Primary Education schools. Our purpose was for the students to realize that Culture refers to all the levels of Social and Economic reality of a country, counted as one of the important elements of Economic development and Social cohesion (Giddens, 2001; Gross, 2003). Also that it is one of the main pillars of Sustainable development, through sustained and functional interdependence with it and also with the environment and economy (Kampouropoulou et al., 2010). For the reasons above, we visited the town of Lindos and students asked as an exercise to "Discover the traditional village of Lindos through Art and Geometry". They had to explore the houses which have features of the Aegean architecture, they follow a continuous building system and their architecture typology is consisted of geometric shapes (Kampouropoulou \& Fokiali, 2011).

\section{Students' Views on Art Education and Creations of Artistic Forms}

149 students of the University of the Aegean, DepArtment of Primary Education, pArticipated in the survey before and after the lectures in the specific lesson. 31 of them were men, $20.81 \%$ and 118 women, $79.19 \%$. When asked "Do you think the course will help you to develop painting skills?" a $0.67 .00 \%$ of the students answered "Strongly disagree", $08.72 .00 \%$ "Disagree", $46.31 \%$ "Neither agree or disagree", a $32.21 \%$ "Agree" and $12.08 \%$ "Strongly agree". After the lectures, exercises and painting activities, the views above differed (Table 1, Figure 1).

Table 1. Variations on whether the course will help in developing painting skills

\begin{tabular}{lcccc}
\hline & \multicolumn{2}{c}{ Pre } & \multicolumn{2}{c}{ Post } \\
\cline { 2 - 5 } & Frequency & Percentage & Frequency & Percentage \\
\hline Strongly disagree & 1 & $00.67 \%$ & 0 & $00.00 \%$ \\
Disagree & 13 & $08.72 \%$ & 0 & $00.00 \%$ \\
Neither agree or disagree & 69 & $46.31 \%$ & 25 & $16.78 \%$ \\
Agree & 48 & $32.21 \%$ & 75 & $50.34 \%$ \\
Strongly agree & 18 & $12.08 \%$ & 49 & $32.89 \%$ \\
\hline Ensemble & 100 & $100.00 \%$ & 100 & $100.00 \%$ \\
\hline
\end{tabular}


As shown in Table 1, many of the students at the end of the semester think that the course was very interesting and promoted their painting skills.

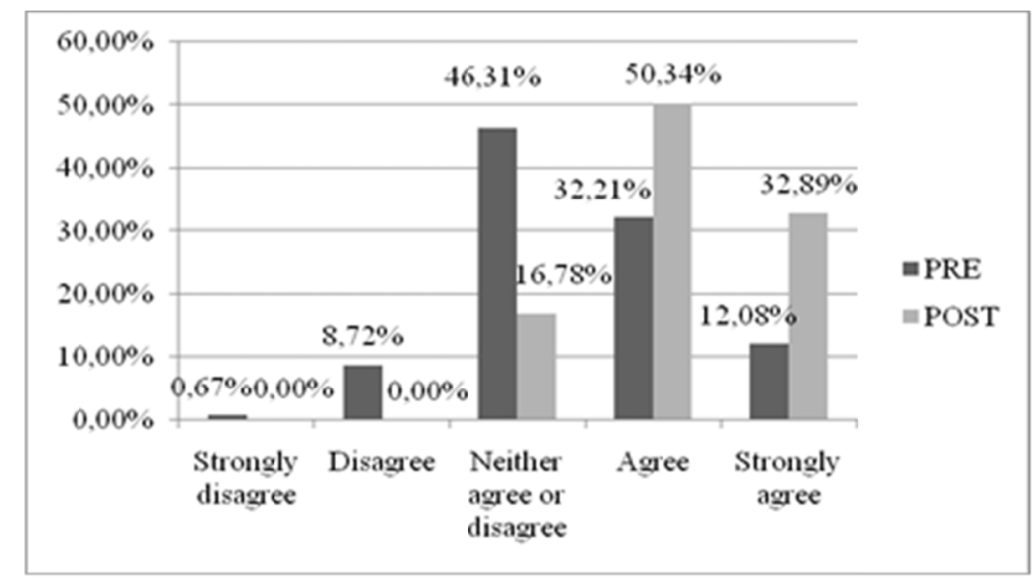

Figure 1. Do you think the course will help you to develop painting skills?

To the question "do you think that the course will help you develop skills in other visual Arts than painting?", a $0.67 .00 \%$ of the students answered "Strongly disagree", $13.42 .00 \%$ "Disagree", $49.66 \%$ "Neither agree or disagree", a 30.87\% "Agree" and 05.37\% "Strongly agree". After the lectures, exercises and painting activities, the views above differed (Tab. 2, Fig. 2).

Table 2. Variations on whether the course will help in developing skills in other visual Arts than painting

\begin{tabular}{lcccc}
\hline & \multicolumn{2}{c}{ Pre } & Post \\
\cline { 2 - 5 } & Frequency & Percentage & Frequency & Percentage \\
\hline Strongly disagree & 1 & $00.67 \%$ & 0 & $00.00 \%$ \\
Disagree & 20 & $13.42 \%$ & 0 & $00.00 \%$ \\
Neither agree or disagree & 74 & $49.66 \%$ & 17 & $16.78 \%$ \\
Agree & 46 & $30.87 \%$ & 77 & $50.34 \%$ \\
Strongly agree & 8 & $05.37 \%$ & 55 & $32.89 \%$ \\
\hline Ensemble & 100 & $100.00 \%$ & 100 & $100.00 \%$ \\
\hline
\end{tabular}

As shown in Table 2, many of the students at the end of the semester think that the course was very interesting and helpful in promoting their different skills in other visual Arts than painting.

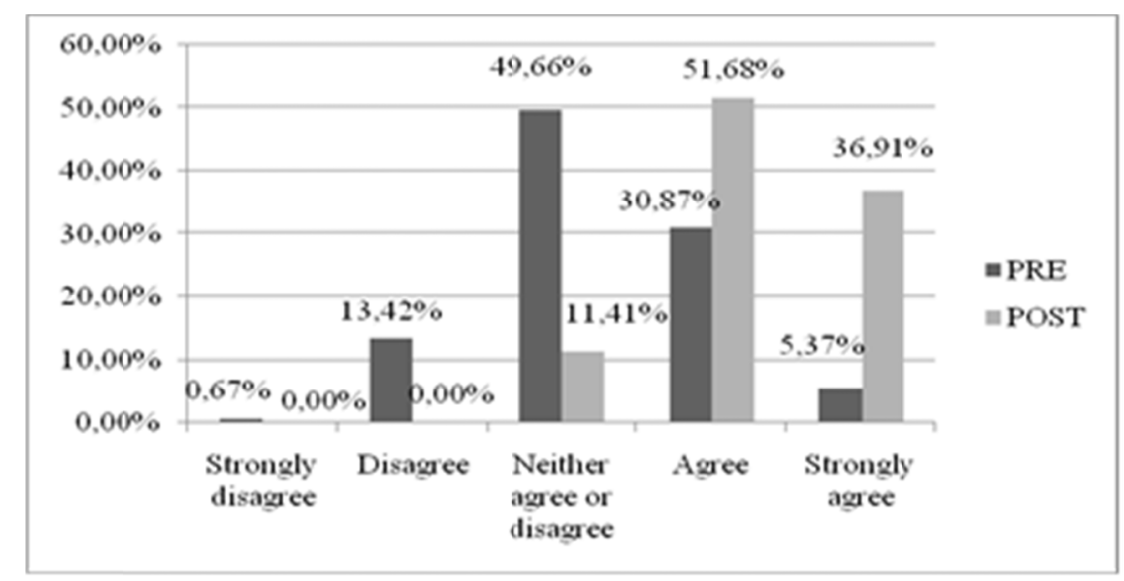

Figure 2. Do you think the course will help you to develop skills in other visual Arts than painting? 
To the question "do you think that the course will help you learn about the role of Cultural Heritage in Art?" a $03.36 \%$ of the students answered "Strongly disagree", $10.74 \%$ "Disagree", $38.93 \%$ "Neither agree or disagree", a $34.90 \%$ "Agree" and $12.08 \%$ "Strongly agree". After the lectures, exercises and painting activities, the views above differed (Table 3, Figure 3).

Table 3. Variations on whether the course will help them to learn about the role of cultural heritage in art

\begin{tabular}{lcccc}
\hline & \multicolumn{2}{c}{ Pre } & \multicolumn{2}{c}{ Post } \\
\cline { 2 - 5 } & Frequency & Percentage & Frequency & Percentage \\
\hline Strongly disagree & 5 & $03.36 \%$ & 1 & $00.67 \%$ \\
Disagree & 16 & $10.74 \%$ & 4 & $02.68 \%$ \\
Neither agree or disagree & 58 & $38.93 \%$ & 25 & $16.78 \%$ \\
Agree & 52 & $34.90 \%$ & 50 & $33.56 \%$ \\
Strongly agree & 18 & $12.08 \%$ & 69 & $46.31 \%$ \\
\hline Ensemble & 100 & $100.00 \%$ & 100 & $100.00 \%$ \\
\hline
\end{tabular}

As shown in Table 3, many of the students at the end of the semester think that the course helped a lot to realize the important role of Cultural Heritage.

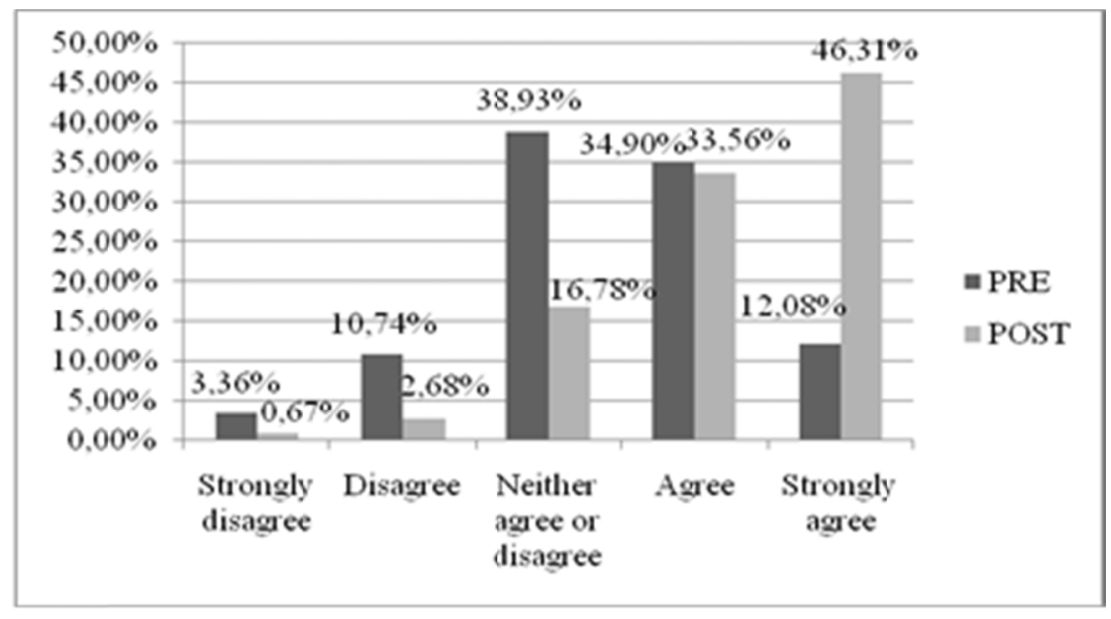

Figure 3. Do you think that the course will help you learn about the role of cultural heritage in art?

To the question "do you believe that the course can contribute to the awareness of the Artistic side of Cultural Heritage?" a $02.01 \%$ of the students answered "Strongly disagree", 12.08.\% "Disagree", 32.89\% "Neither agree or disagree", a 28.19\% "Agree", 13.42\% "Strongly agree" and 11.41\% "no answer". After the lectures, exercises and painting activities, the views above differed (Table 4, Figure 4).

Table 4. Variations on whether the course will help them to learn about the role of cultural heritage in art

\begin{tabular}{lcccc}
\hline & \multicolumn{2}{c}{ Pre } & \multicolumn{2}{c}{ Post } \\
\cline { 2 - 5 } & Frequency & Percentage & Frequency & Percentage \\
\hline Strongly disagree & 3 & $02.01 \%$ & 1 & $00.67 \%$ \\
Disagree & 18 & $12.08 \%$ & 0 & $00.00 \%$ \\
Neither agree or disagree & 49 & $32.89 \%$ & 9 & $06.04 \%$ \\
Agree & 42 & $28.19 \%$ & 59 & $39.60 \%$ \\
Strongly agree & 20 & $13.42 \%$ & 80 & $53.69 \%$ \\
No answer & 17 & $11.41 \%$ & 0 & $00.00 \%$ \\
Ensemble & 100 & $100.00 \%$ & 100 & $100.00 \%$ \\
\hline
\end{tabular}

As shown in Table 4, most of the students at the end of the semester think that the course helped a lot to realize the Artistic side of Cultural Heritage. 


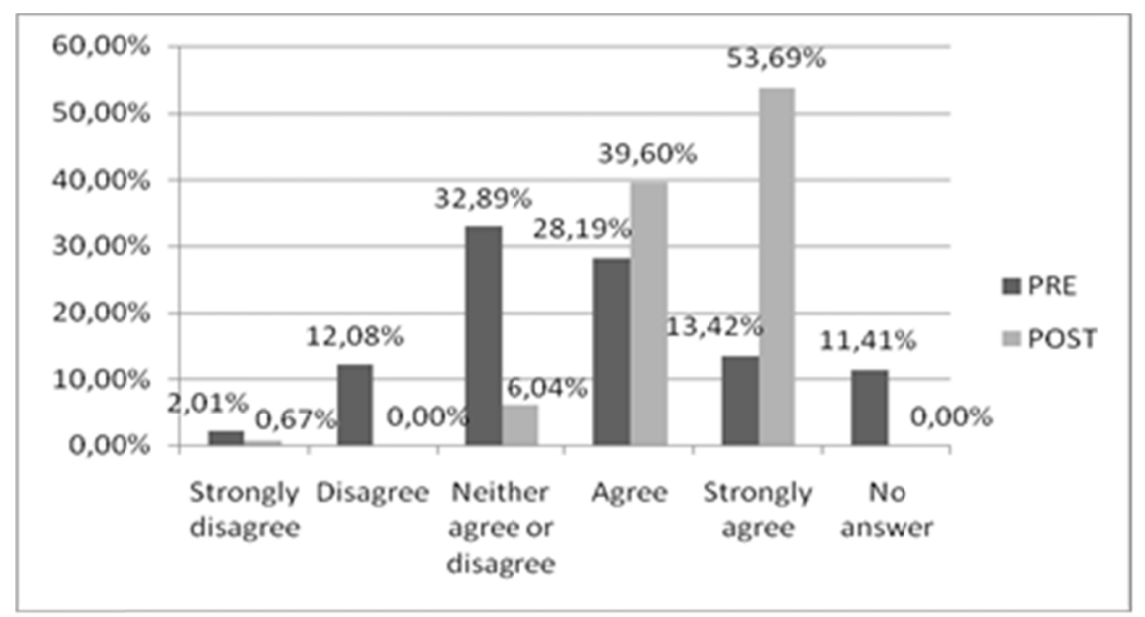

Figure 4. Do you believe that the course can contribute to the awareness of the Artistic side of Cultural Heritage?

To the question "do you believe that the course may be a source of inspiration for new creations?" a $01.34 \%$ of the students answered "Strongly disagree", $02.68 . \%$ "Disagree", 27.52\% "Neither agree or disagree", a 40.27\% "Agree" and $22.82 \%$ "Strongly agree" and $05.37 \%$ "no answer". After the lectures, exercises and painting activities, the views above differed (Table 5, Figure 5).

Table 5. Variations on whether the course may will be a source of inspiration for new creations

\begin{tabular}{lcccc}
\hline & \multicolumn{2}{c}{ Pre } & \multicolumn{2}{c}{ Post } \\
\cline { 2 - 5 } & Frequency & Percentage & Frequency & Percentage \\
\hline Strongly & 2 & $02.01 \%$ & 1 & $00.67 \%$ \\
disagree & & & & $00.00 \%$ \\
Disagree & 4 & $12.08 \%$ & 3 & $06.04 \%$ \\
$\begin{array}{l}\text { Neither agree or } \\
\text { disagree }\end{array}$ & 41 & $32.89 \%$ & 17 & \\
Agree & 60 & $28.19 \%$ & 49 & $39.60 \%$ \\
Strongly agree & 34 & $13.42 \%$ & 79 & $53.69 \%$ \\
\hline No answer & 8 & $05.37 \%$ & 0 & $00.00 \%$ \\
\hline Ensemble & 100 & $100.00 \%$ & 100 & $100.00 \%$ \\
\hline
\end{tabular}

As shown in Table 5, many of the students at the end of the semester think that the course maybe a source of inspiration for new creations.

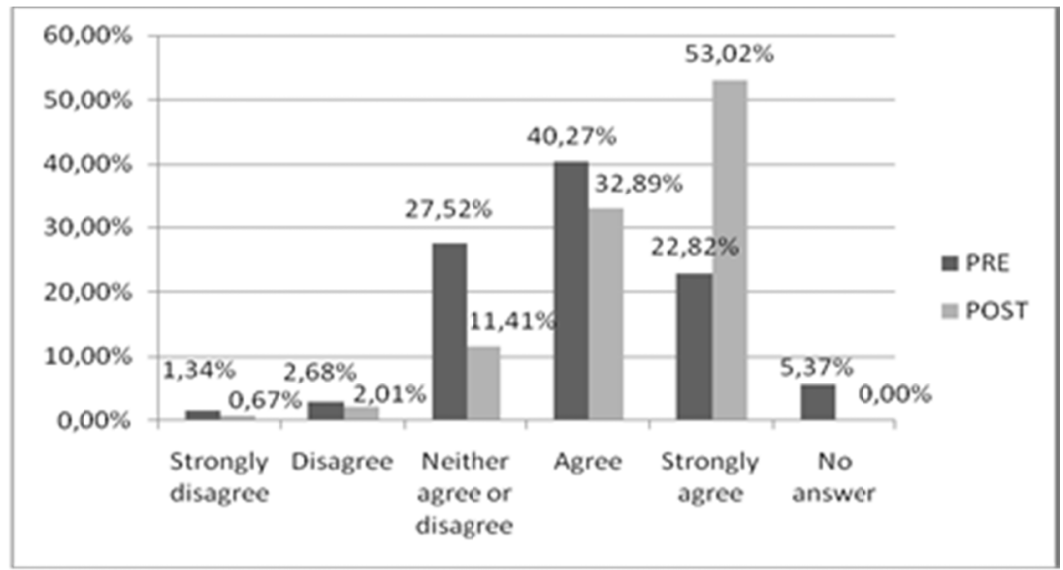

Figure 5. Variations on whether the course may will be a source of inspiration for new creations. 
To the question "do you think you can create training manual that would help your students to experience the Cultural Heritage?" a $06.04 \%$ of the students answered "Strongly disagree", 27.52\% "Disagree", 46.98\% "Neither agree or disagree", a $14.77 \%$ "Agree" $04.70 \%$ and "Strongly agree". After the lectures, exercises and painting activities, the views above differed (Table 6, Figure 6).

Table 6. Variations on whether the course may will be a source of inspiration for new creations

\begin{tabular}{lcccc}
\hline & \multicolumn{2}{c}{ Pre } & \multicolumn{2}{c}{ Post } \\
\cline { 2 - 5 } & Frequency & Percentage & Frequency & Percentage \\
\hline Strongly disagree & 9 & $06.04 \%$ & 1 & $00.67 \%$ \\
Disagree & 41 & $27.52 \%$ & 5 & $03.67 \%$ \\
Neither agree or disagree & 70 & $46.98 \%$ & 25 & $16.78 \%$ \\
Agree & 22 & $14.77 \%$ & 62 & $41.61 \%$ \\
Strongly agree & 07 & $04.70 \%$ & 56 & $04.70 \%$ \\
\hline Ensemble & 100 & $100.00 \%$ & 100 & $100.00 \%$ \\
\hline
\end{tabular}

As shown in Table 6, many of the students at the end of the semester were able to create training manual for their students so, they could experience the Cultural Heritage.

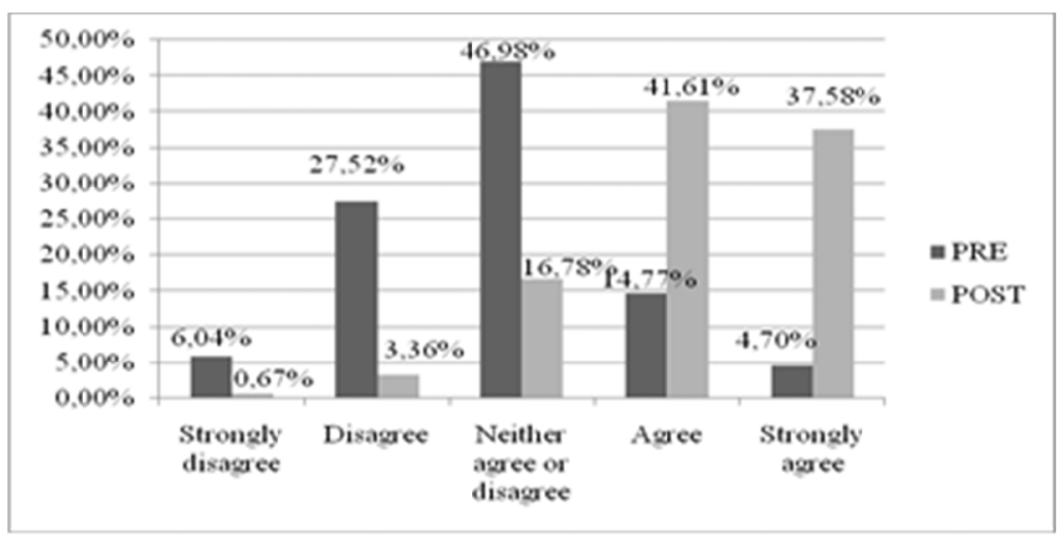

Figure 6. Do you can create training manual that would help your students to experience the Cultural Heritage?

To the question "how much the course in conjunction with the Cultural Heritage could assist in the Economic growth of our country?" a $08.05 \%$ of the students answered "Strongly disagree", $30.87 \%$ "Disagree", $30.87 \%$ "Neither agree or disagree", $21.48 \%$ "Agree" and $08.72 \%$ "Strongly agree". After the lectures, exercises and painting activities, the views above differed (Table 7, Figure 7).

Table 7. Variations on whether the course in conjunction with the Cultural Heritage could assist in the Economic development of their country

\begin{tabular}{lcccc}
\hline & \multicolumn{2}{c}{ Pre } & \multicolumn{2}{c}{ Post } \\
\cline { 2 - 5 } & Frequency & Percentage & Frequency & Percentage \\
\hline Strongly disagree & 12 & $08.05 \%$ & 1 & $00.67 \%$ \\
Disagree & 46 & $30.87 \%$ & 2 & $01.34 \%$ \\
Neither agree or disagree & 46 & $30.87 \%$ & 31 & $20.81 \%$ \\
Agree & 32 & $21.48 \%$ & 59 & $39.60 \%$ \\
Strongly agree & 13 & $08.72 \%$ & 56 & $37.58 \%$ \\
\hline Ensemble & 100 & $100.00 \%$ & 100 & $100.00 \%$ \\
\hline
\end{tabular}

As shown in Table 7, most of the students believe that the course in conjunction with the Cultural Heritage could assist in the Economic development of their country. 


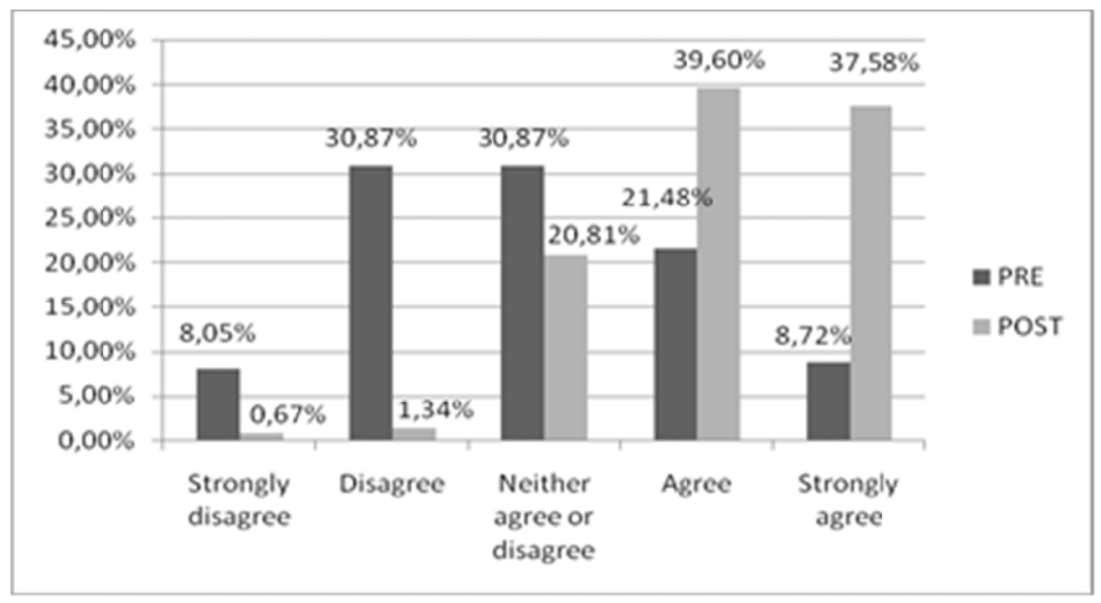

Figure 7. How much the course in conjunction with the Cultural Heritage could assist in the Economic development of your country?

To the question "how much the course in conjunction with the Cultural Heritage could assist in the Social development of our country?" a $00.67 \%$ of the students answered "Strongly disagree", $11.41 \%$ "Disagree", $42.95 \%$ "Neither agree or disagree", 29.53\% "Agree" and 15.44\% "Strongly agree". After the lectures, exercises and painting activities, the views above differed (Tab. 8, Fig. 8).

Table 8. Variations on whether the course in conjunction with the Cultural Heritage could assist in the Social development of their country

\begin{tabular}{lcccc}
\hline & \multicolumn{2}{c}{ Pre } & \multicolumn{2}{c}{ Post } \\
\cline { 2 - 5 } & Frequency & Percentage & Frequency & Percentage \\
\hline Strongly disagree & 1 & $00.67 \%$ & 1 & $00.67 \%$ \\
Disagree & 17 & $11.41 \%$ & 6 & $04.03 \%$ \\
Neither agree or disagree & 64 & $42.95 \%$ & 35 & $23.49 \%$ \\
Agree & 44 & $29.53 \%$ & 51 & $34.23 \%$ \\
Strongly agree & 23 & $15.44 \%$ & 56 & $37.58 \%$ \\
\hline Ensemble & 100 & $100.00 \%$ & 100 & $100.00 \%$ \\
\hline
\end{tabular}

As shown in Table 8, most of the students believe that the course in conjunction with the Cultural Heritage could assist in the Social development of their country.

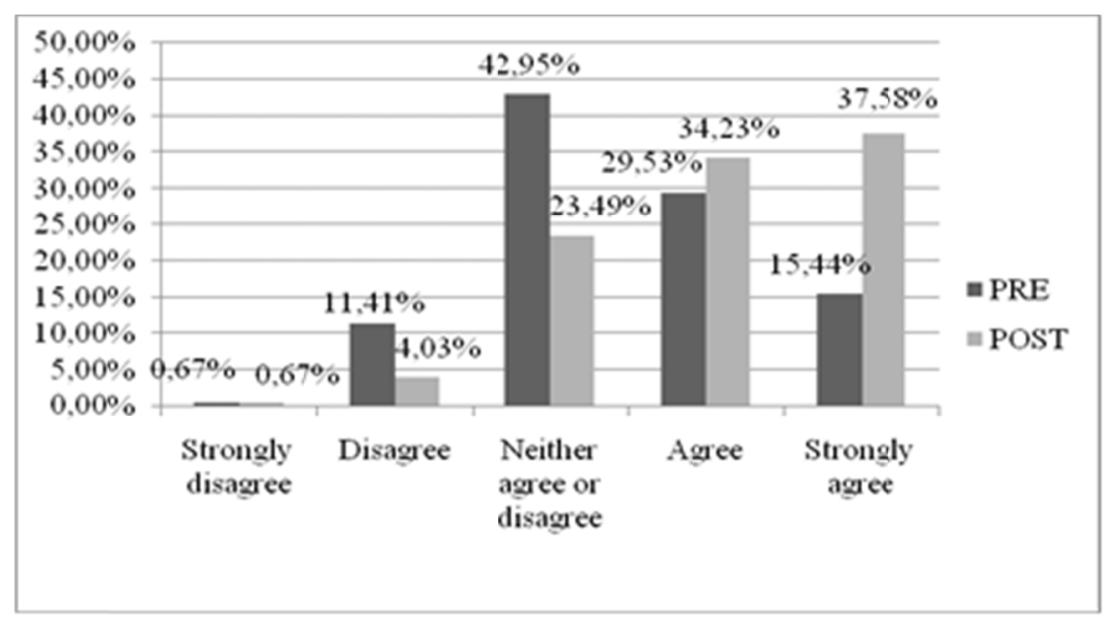

Figure 8. How much the course in conjunction with the Cultural Heritage could assist in the Social development of your country? 
To the question "how much the course in conjunction with the Cultural Heritage could assist in the Cultural development of our country?" a $00.67 \%$ of the students answered "Strongly disagree", $08.05 \%$ "Disagree", $36.91 \%$ "Neither agree or disagree", $28.86 \%$ "Agree" and $25.50 \%$ "Strongly agree". After the lectures, exercises and painting activities, the views above differed (Table 9, Figure 9).

Table 9. Variations on whether the course in conjunction with the Cultural Heritage could assist in the Cultural development of their country

\begin{tabular}{lcccc}
\hline & \multicolumn{2}{c}{ Pre } & \multicolumn{2}{c}{ Post } \\
\cline { 2 - 5 } & Frequency & Percentage & Frequency & Percentage \\
\hline Strongly disagree & 1 & $00.67 \%$ & 1 & $00.67 \%$ \\
Disagree & 12 & $08.05 \%$ & 2 & $01.34 \%$ \\
Neither agree or disagree & 55 & $36.91 \%$ & 14 & $09.40 \%$ \\
Agree & 43 & $28.86 \%$ & 62 & $41.61 \%$ \\
Strongly agree & 38 & $25.50 \%$ & 70 & $46.98 \%$ \\
\hline Ensemble & 100 & $100.00 \%$ & 100 & $100.00 \%$ \\
\hline
\end{tabular}

As shown in Table 9, students at the end of the semester believe that the course in conjunction with the Cultural Heritage could assist in the Cultural development of their country.

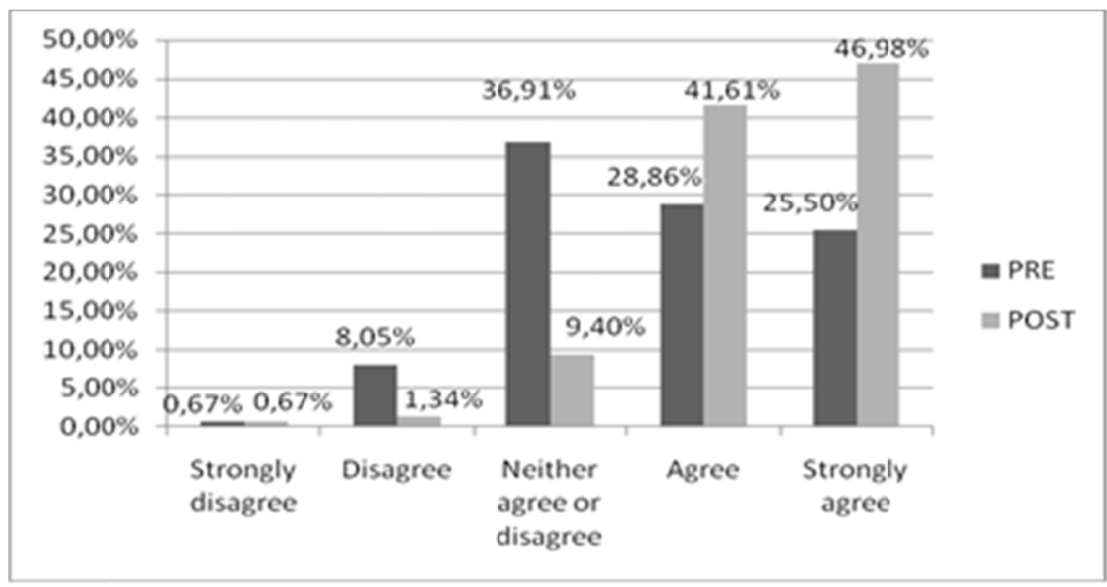

Figure 9. How much the course in conjunction with the Cultural Heritage could assist in the Cultural development of your country?

To the question "how much the course in conjunction with the Cultural Heritage could assist in the Sustainable development of our country?" a $05.37 \%$ of the students answered "Strongly disagree", $31.54 \%$ "Disagree", $38.31 \%$ "Neither agree or disagree", $17.45 \%$ "Agree" and $06.71 \%$ "Strongly agree". After the lectures, exercises and painting activities, the views above differed (Tab. 10, Fig. 10).

Table 10. Variations on whether the course in conjunction with the Cultural Heritage could assist in the Sustainable development of their country

\begin{tabular}{lcccc}
\hline & \multicolumn{2}{c}{ Pre } & \multicolumn{2}{c}{ Post } \\
\cline { 2 - 5 } & Frequency & Percentage & Frequency & Percentage \\
\hline Strongly disagree & 5 & $05.37 \%$ & 1 & $00.67 \%$ \\
Disagree & 47 & $31.54 \%$ & 2 & $01.34 \%$ \\
Neither agree or disagree & 58 & $38.93 \%$ & 30 & $20.13 \%$ \\
Agree & 26 & $17.45 \%$ & 69 & $46.31 \%$ \\
Strongly agree & 10 & $06.71 \%$ & 47 & $31.54 \%$ \\
\hline Ensemble & 100 & $100.00 \%$ & 100 & $100.00 \%$ \\
\hline
\end{tabular}

As shown in Table 10, students at the end of the semester believe that the course in conjunction with the Cultural 
Heritage could assist in the Sustainable development of their country.

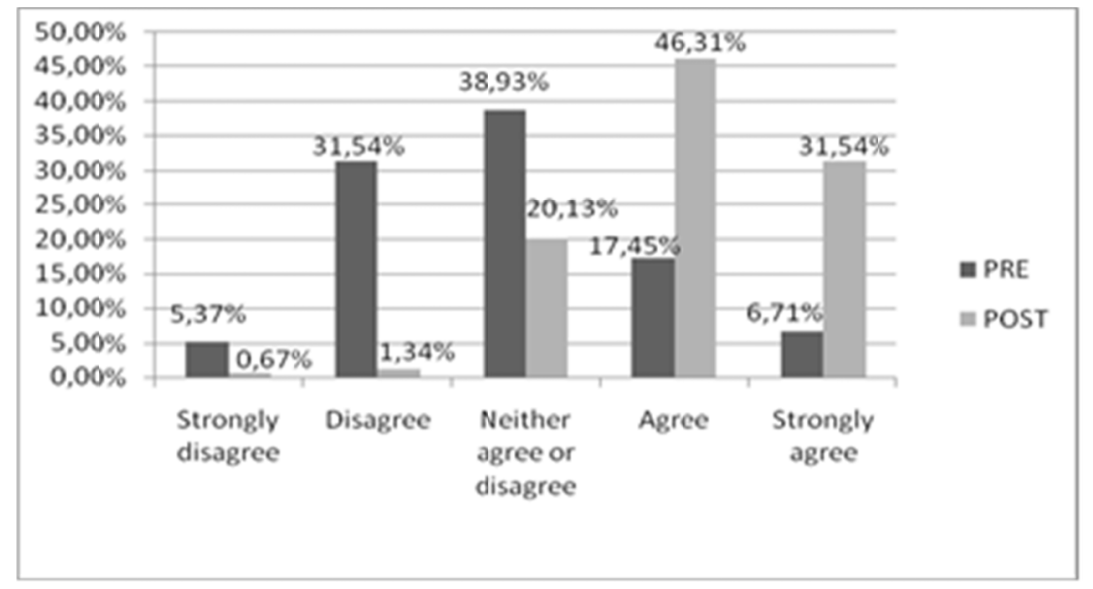

Figure 10. How much the course in conjunction with the Cultural Heritage could assist in the Sustainable development of your country?

\section{Conclusions}

Students developed their abilities and realized that art is ever so important for Education and even more that Culture, Art and Cultural Education are interrelated elements (Kampouropoulou-Savvaidou, 2007). The goal of this study was to appoint srudents' variations before and after the course "Art Education and Creations of Artistic Forms" related to general knowledge cpmbined with general characteristics of Art and its special meaning and combination with the promotion of locall Art and also Cultural Heritage. The students came along a specific Art course, completed their exercises in Art works and after the completion they answered a questionnaire so uw to explore and evaluate their views towards the lesson. This search hopefully will help the promotion of Arts' meaning and the significance in both, human and Primary students' lives. The new method in teaching practice inn Higher Education, we suppose that creates a new path for future researchers on this study (Athanasiadis \& Stefos, 2006).

\section{References}

Ardoin, I. (2002). The Artistic actions at school. Athens, Nefele.

Athanasiadis, I., \& Stefos, E. (Eds.) (2006). Interdisciplinary technological approaches. Applications in the High school of Ialyssos. (pp. 36-40). Minicipal Library of Ialyssos.

Balta, B., \& Demou, H. (2002). A Journey to the Art of Ancient World: an instructional activity to investigate the possibility teaching the ancient Art using ICT. Proccedings of the $3^{\text {rd }}$ Conference. Athens, Kastaniotis.

Bruner, J. S. (1966). Toward a theory of Instruction. Cambridge Mass: Harvard University Press.

Chapman, L. (1993). Art Education. Approaches to Art in Education. Athens, Nefele.

Dottrens, R. (1974). Tutor and Teach. The school pedagogy and special teaching of modern elementary school. Athens, Diptycho-Unesco.

Fokiali, P., Kampouropoulou, M., \& Konsolas, M. (2003). Sustainable Development, Art and linguistic communication. Teaching children of primary school to plan the future of their country. Pedagogikos Logos.

Giddens, A. (2001). The world of rapid change. How globalization affects our lives. Athens, Metaihmio.

Girtzi, M., \& Boundidou, A. (2010). Disigning activities by utilizing new technologies to the educational program: Travelling to Aegea of Macedonia for the royal wedding. Proceedings of the $2^{\text {nd }}$ Jellenic Educational Conference. Imathia.

Gross, D. (2003). The ruins of the past. Athens, Patakis.

Guilford, J. P. (1952). Some recent findings on thinking abilities and their implications. International Bulletin, U.S. Air Force, 3(3).

Kampouropoulou - Savvaidou, M. (2007). New Technologies and Education Sciences. Athens. Metaichmio.

Kampouropoulou, M., Athanasiadis, I., \& Stefos, E. (2001). Students' Views on the Use of New Technologies in 
Art Education: An Interdisciplinary approach to Higher Education, Review of European Studies, 3(1).

Kampouropoulou, M., \& Fokiali, P. (2011). The secret Geometry of Traditional Aegean settlement. Geometry Art and sustainable development in an interdisciplinary educational project. University of the Aegean, Rhodes.

Kampouropoulou, M., Fokiali, P., \& Nikolaou, A. (2010). Targeted interventions with focus on Sustainability, Culture and Awareness of local societies. The case of Educational projects of the University of the Aegean. Proceedings of the $1^{\text {st }}$ Panhellenic Conference with International PArticipation "Local Communities and higher Educational Institutions". Coexistence for Sustainable Development, Rhodes.

Kampouropoulou, M., Fokiali, P., Athanasiadis, I., \& Stefos, E. (2011). Teaching Art using Technology: The views of High School students in Greece. Review of European Studies, 3(2).

Matsagouras, I. (2002). Interdisciplinarity and Cross-thematic Curicula: Ways of organizing school knowledge. Review of Educational Affairs, 7, 19-36.

Mikropoulos, A., Diplas, K., Pidelas, P., Chalkidis, A., \& Giakovis. D. (1994). Virtual Reality and Education. A new tool or methodology. Proceedings of the $2^{\text {nd }}$ Conference on Informatics in Education. Athens.

Robinson, K. (Ed.) (1990). The Arts 5-16: A Curriculum Framework. Essex: Oliver \& Boyd.

Rogers, R. (1995). Guaranteeing an Entitlement to the Arts in Schools. London: Royal Society for the Encouragment of Arts, Manifactures and Commerce (RSA).

Skarpelos, J. (2000). Historical Memory and Hellenism in Comics. Athens, Kritiki.

\section{Copyrights}

Copyright for this article is retained by the author(s), with first publication rights granted to the journal.

This is an open-access article distributed under the terms and conditions of the Creative Commons Attribution license (http://creativecommons.org/licenses/by/3.0/). 